\title{
Research on the Influence of Straddle-Type Monorail's Pantograph Head Parameter on Power Collection Quality
}

\author{
Zhen Yang $^{1} \cdot$ Zixue Du$^{1} \cdot$ Cheng Chen ${ }^{1} \cdot$ Xiaoxia Wen ${ }^{1} \cdot$ Zhouzhou Xu $^{1}$
}

Received: 6 July 2017/Revised: 4 September 2017/Accepted: 11 September 2017/Published online: 9 November 2017

(c) The Author(s) 2017. This article is an open access publication

\begin{abstract}
At present, the coupling relationship between the pantograph and catenary is not ideal for straddle-type monorail. The power collection quality is poor, and the wear of the contact strip of a pantograph is uneven. Therefore, the key problem of coupling relation between the pantograph and catenary is the dynamics of a pantograph-catenary system. This paper analyzed the modal of catenary through simulation with finite element model and the vibration modal of pantograph multi-rigidbody dynamic model by simulation in multi-body danamics software ADAMS. A rigid-flexible coupling dynamic model of pantograph-catenary system is established. Finally, extensive research has been made on the influence of pantograph head parameters on the power collection quality.
\end{abstract}

Keywords Straddle-type monorail $\cdot$ Power collection quality · Contact strip · Rigid-flexible coupling ·

Pantograph head parameters

Zhen Yang

yangz0000@163.com

Zixue Du

aaadzx@163.com

Cheng Chen

705479475@qq.com

Xiaoxia Wen

963884811@qq.com

Zhouzhou Xu

33243665@qq.com

1 Chongqing Jiaotong University, No. 66 Xuefu Road, Nan'an District, Chongqing, China

Editor: Eryu Zhu

\section{Introduction}

The track of straddle-type monorail consists of a PC beam which is made of concrete, and the positive and negative catenaries are rigidly installed along the two sides of the PC beam [1]. Because of the particular wheel-rail coupling relationship and the collection modes, the coupling relation between the pantograph and catenary in the straddle-type monorail is very different from other systems. Therefore, the aims to ameliorate coupling relation and improve the power collection quality between pantograph and catenary are of great significance and will serve to improve the safety of the operation of straddle-type monorail.

\section{Power Collection Quality Evaluation Index Between Pantograph and Catenary}

There is no power collection quality standard for straddletype monorail. This paper proposed power collection quality standard for straddle-type monorail on the basis of railway standards TB/T 3271-2011 and the experience of straddle-type monorail operations in Chongqing.

\subsection{The Average Value of Contact Force $F_{m}$}

Contact force $F$ is the most important technical index to characterize the dynamic parameters of the pantograph-catenary system. It is also the sum of the forces that are applied to the catenary by the pantograph. In the coupling process between the pantograph and catenary, the average value of the contact force between the pantograph and catenary is:

$F_{m}=\frac{\sum F_{i}}{n}$ 
where $F_{i}$ is the sampling value of the contact force, $i=1$, $2, \ldots, n$

$n$ is the number of samples of contact force in the statistics section.

\subsection{The Standard Deviation of Contact Forces}

The standard deviation of contact force between pantograph and catenary can be calculated through statistical knowledge, and the standard deviation of the contact force is within a certain range:

$s=\sqrt{\frac{\sum\left(F_{i}-F_{m}\right)^{2}}{n-1}}$.

\subsection{Maximum and Minimum Contact Force}

The maximum and minimum contact force is the actual maximum contact force and the minimum contact force exists between the pantograph and catenary when the vehicle passes the evaluation section.

\subsection{Off-Line Rate}

Off-line is defined as the condition that the contact force between the pantograph and catenary is zero. Off-line rate is calculated by evaluating the ratio of the sum of the offline distance to the total distance length when the vehicle passes the evaluation section.

The contact force between the pantograph and catenary of straddle-type monorail should be in the range of 44-79 $\mathrm{N}$ in the whole working stroke, and in the range of $59_{-10}^{+10} \mathrm{~N}$ in normal working positions. Therefore, according to evaluation index system in this study, the maximum contact force between the pantograph and catenary should be less than $79 \mathrm{~N}$, the minimum contact force between the pantograph and catenary should be greater than $44 \mathrm{~N}$, and the optimum mean contact force should also be in the range of $59_{-10}^{+10} \mathrm{~N}$ [2]. The standard deviation of contact force directly reflects the fluctuation range of contact forces. The smaller the standard deviation is, the smaller the fluctuation range of the contact force is, and the better the power collection quality.

\section{Dynamic Model of Pantograph}

\subsection{Two-Dimensional Model of Pantograph}

Straddle-type monorail pantograph (Fig. 1) is mainly composed of a bottom plate, a lower frame, an upper frame, a connecting rod, a balance bar, a pantograph head

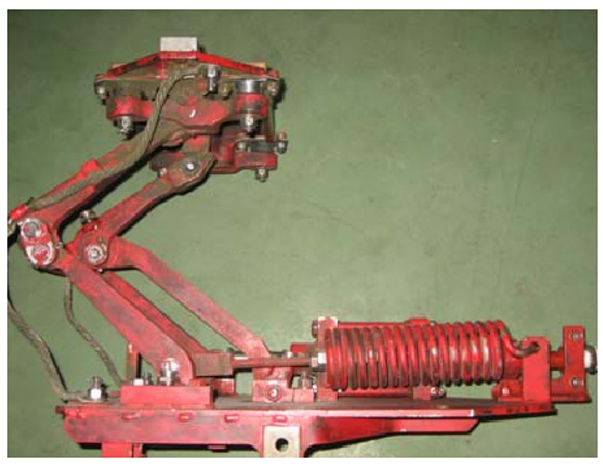

Fig. 1 Pantograph

seat, a pantograph spring, a pantograph head and cylinder parts (positive pantograph only) and so on.

The pantograph is reduced to the model shown in Fig. 2. $\alpha$ is the angle between $A C$ and $X$ axis, $\beta$ is the angle between $B D$ and $X$ axis, $\gamma$ is the angle between $C D$ and $X$ axis, $\delta$ is the angle between $A B$ and $X$ axis, $\varepsilon$ is the angle between $C D$ and $C G, \theta$ is the angle between $F G$ and $X$ axis. $F c$ is the contact force between the pantograph head and catenary. The direction of the vehicle operation is defined as the positive direction of the $X$ axis, the yaw direction of the vehicle is defined as the $Y$ axis, and the vertical upward direction is the positive direction of the $Z$ axis.

\subsection{Dynamic Computational Model of Pantograph}

The motion differential equations of pantograph head components are established on the basis of Newton's second law.

$m_{h} \ddot{z}_{h}=F_{h}-F_{c}$

where $m_{h}$ is the weight of pantograph head component, $Z_{h}$ is the vertical displacement of pantograph head component,

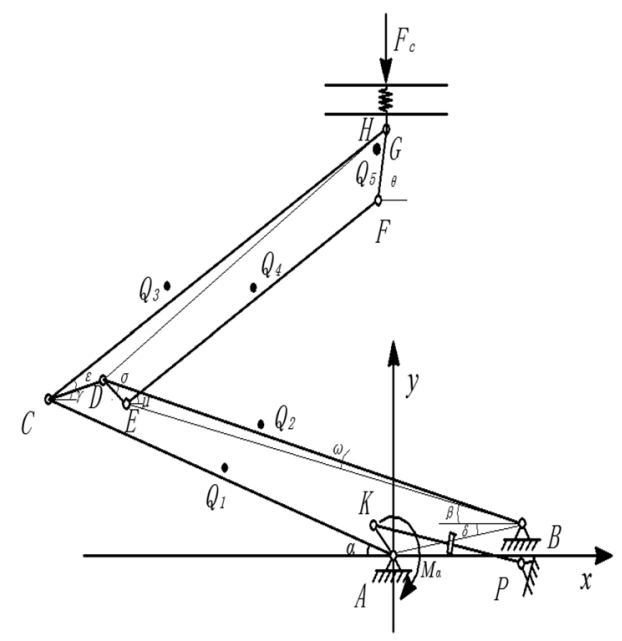

Fig. 2 Two-dimensional model of pantograph 
$F_{c}$ is the contact force between the head of the pantograph and the catenary

$F_{h}=-k_{h}\left(y_{h}-y_{G}-\Delta l_{0}\right)-c_{h}\left(\dot{y}_{h}-\dot{y}_{G}\right)$

where $k_{h}, c_{h}$ are the stiffness and damping of elastic elements of the pantograph head, $\Delta l_{0}$ is the natural length of the elastic element.

The frame portion of the pantograph has only one degree of freedom, so the angle $\alpha$ can be regarded as an independent variable. According to Lagrange equation:

$\frac{d}{\mathrm{~d} t} \frac{\partial L}{\partial \dot{\alpha}}-\frac{\partial L}{\partial \alpha}=Q_{\alpha}$

where $Q_{\alpha}$ is the generalized force, $L=T-V . T$ is the total kinetic energy of the frame system, $V$ is the total potential energy of a frame system, $V=0$.

$T=T_{\text {Lower }}+T_{\mathrm{LG}}+T_{\mathrm{Upper}}+T_{\mathrm{UG}}+T_{\mathrm{H}}$

where $T_{\mathrm{Lower}}, T_{\mathrm{LG}}, T_{\mathrm{Upper}}, T_{\mathrm{UG}}, T_{\mathrm{H}}$ are the kinetic energy of the lower frame, the connecting rod, the upper frame, the balance bar and the pantograph head support, respectively.

Kinetic energy of the lower frame:

$$
\begin{aligned}
T_{\text {Lower }}= & \frac{1}{2} J_{1} \dot{\alpha}^{2}+\frac{1}{2} m_{1}\left(\dot{x}_{Q_{1}}^{2}+\dot{y}_{Q_{1}}^{2}\right) \\
= & \frac{1}{2} J_{1} \dot{\alpha}^{2}+\frac{1}{2} m_{1}\left[\dot{x}_{A}^{2}+\dot{y}_{A}^{2}+l_{A Q_{1}}^{2} \dot{\alpha}^{2}\right. \\
& +2 l_{A Q_{1}} \sin \left(\alpha+\angle C A Q_{1}\right) \cdot \dot{x}_{A} \dot{\alpha} \\
& \left.+2 l_{A Q_{1}} \cos \left(\alpha+\angle C A Q_{1}\right) \cdot \dot{y}_{A} \dot{\alpha}\right]
\end{aligned}
$$

Kinetic energy of the connecting rod:

$$
\begin{aligned}
T_{\mathrm{LG}}= & \frac{1}{2} J_{2} \dot{\beta}^{2}+\frac{1}{2} m_{2}\left(\dot{x}_{Q_{2}}^{2}+\dot{y}_{Q_{2}}^{2}\right) \\
= & \frac{1}{2} J_{2} \dot{\beta}^{2}+\frac{1}{2} m_{2}\left[\dot{x}_{A}^{2}+\dot{y}_{A}^{2}+l_{B Q_{2}}^{2} \dot{\beta}^{2}\right. \\
& +2 l_{B Q_{2}} \sin \left(\beta+\angle D B Q_{2}\right) \cdot \dot{x}_{A} \dot{\beta} \\
& \left.+2 l_{B Q_{2}} \cos \left(\beta+\angle D B Q_{2}\right) \cdot \dot{y}_{A} \dot{\beta}\right]
\end{aligned}
$$

Kinetic energy of upper frame:

$$
\begin{aligned}
T_{\mathrm{Upper}}= & \frac{1}{2} J_{3} \dot{\gamma}^{2}+\frac{1}{2} m_{3}\left(\dot{x}_{Q_{3}}^{2}+\dot{y}_{Q_{3}}^{2}\right) \\
= & \frac{1}{2} J_{3} \dot{\gamma}^{2}+\frac{1}{2} m_{3}\left[\dot{x}_{A}^{2}+\dot{y}_{A}^{2}+l_{A C}^{2} \dot{\alpha}^{2}+l_{C Q_{3}}^{2} \dot{\gamma}^{2}\right. \\
& +2 l_{A C} \sin \alpha \cdot \dot{x}_{A} \alpha-2 l_{C Q_{3}} \sin \left(\gamma+\varepsilon+\angle G C Q_{3}\right) \cdot \dot{x}_{A} \dot{\gamma} \\
& +2 l_{A C} \cos \alpha \cdot \dot{y}_{A} \dot{\alpha}+2 l_{C Q_{3}} \cos \left(\gamma+\varepsilon+\angle G C Q_{3}\right) \cdot \dot{y}_{A} \dot{\gamma} \\
& \left.+2 l_{A C} l_{C Q_{3}} \cos \left(a+\gamma+\varepsilon+\angle G C Q_{3}\right) \cdot \dot{\alpha} \dot{\gamma}\right]
\end{aligned}
$$

Kinetic energy of the balance bar:

$$
\begin{aligned}
T_{\mathrm{UG}}= & \frac{1}{2} J_{4} \dot{\mu}^{2}+\frac{1}{2} m_{4}\left(\dot{x}_{Q_{4}}^{2}+\dot{y}_{Q_{4}}^{2}\right) \\
= & \frac{1}{2} J_{4} \dot{\mu}^{2}+\frac{1}{2} m_{4}\left[\dot{x}_{A}^{2}+\dot{y}_{A}^{2}+l_{B E}^{2} \dot{\beta}^{2}+l_{E Q_{4}}^{2} \dot{\mu}^{2}\right. \\
& +2 l_{B E} \sin (\beta-\omega) \cdot \dot{x}_{A} \dot{\beta}-2 l_{E Q_{4}} \sin \mu \cdot \dot{x}_{A} \dot{\mu} \\
& +2 l_{B E} \cos (\beta-\omega) \cdot \dot{y}_{A} \dot{\beta}+2 l_{E Q_{4}} \cos \mu \cdot \dot{y}_{A} \dot{\mu} \\
& \left.+2 l_{B E} l_{E Q_{4}} \cos (\mu+\beta-\omega) \cdot \dot{\beta} \dot{\mu}\right]
\end{aligned}
$$

Kinetic energy of the pantograph head support:

$$
\begin{aligned}
T_{\mathrm{H}}= & \frac{1}{2} J_{5} \dot{\theta}^{2}+\frac{1}{2} m_{5}\left(\dot{x}_{Q_{5}}^{2}+\dot{y}_{Q_{5}}^{2}\right) \\
= & \frac{1}{2} J_{5} \dot{\theta}^{2}+\frac{1}{2} m_{5}\left[\dot{x}_{A}^{2}+\dot{y}_{A}^{2}+l_{B E}^{2} \dot{\beta}^{2}+l_{E F}^{2} \dot{\mu}^{2}+l_{F Q_{5}}^{2} \dot{\theta}^{2}\right. \\
& +2 l_{B E} \sin (\beta-\omega) \cdot \dot{x}_{A} \dot{\beta} \\
& -2 l_{E F} \sin \mu \cdot \dot{x}_{A} \dot{\mu}-2 l_{F Q_{5}} \sin \left(\theta+\angle G F Q_{5}\right) \cdot \dot{x}_{A} \dot{\theta} \\
& +2 l_{B E} \cos (\beta-\omega) \cdot \dot{y}_{A} \dot{\beta} \\
& +2 l_{E F} \cos \mu \cdot \dot{y}_{A} \dot{\mu}+2 l_{F Q_{5}} \cos \left(\theta+\angle G F Q_{5}\right) \cdot \dot{y}_{A} \dot{\theta} \\
& +2 l_{B E} l_{E F} \cos (\mu+\beta-\omega) \cdot \dot{\beta} \dot{\mu} \\
& \left.+2 l_{B E} l_{F Q_{5}} \cos (\beta-\omega+\theta) \cdot \dot{\beta} \dot{\theta}+2 l_{E F} l_{F Q_{5}} \cos (\mu+\theta) \cdot \dot{\mu} \dot{\theta}\right]
\end{aligned}
$$

where $m_{1}, m_{2}, m_{3}, m_{4}, m_{5}$ are the weight of the lower frame, the connecting rod, the upper frame, the balance bar and the pantograph head support, respectively; $J_{1}, J_{2}, J_{3}, J_{4}, J_{5}$ are the inertia around the centroid of the lower frame, the connecting rod, the upper frame, the balance bar and the pantograph head support around the centroid, respectively.

\section{Dynamic Model of Pantograph and Catenary System}

\subsection{Modal Analysis of Catenary}

The paper analyzed the modal of catenary finite element model by Hyperworks [3, 4]. The characteristics of the vibration in structures are composed of linear sets of vibration corresponding to their respective natural modes. The dynamic characteristics of the structure are mainly determined by the low-frequency vibration modes. Therefore, the paper analyzed the modes of the first eight orders. As can be seen from Table 1, with the increase in modal order, the frequency of resonance increases nonlinearly. Figure 3 is the first six order vibration modes of catenary.

\subsection{Dynamic Characteristics Analysis of Pantograph}

The paper analyzed the vibration modal of a pantograph multi-rigid-body dynamic model by ADAMS. Figure 4 is the dynamic analysis of the characteristics of 
Table 1 The first eight order natural frequencies of the catenary (unit: $\mathrm{Hz}$ )

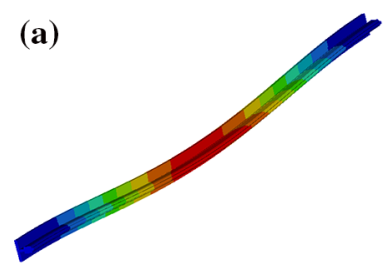

(c)

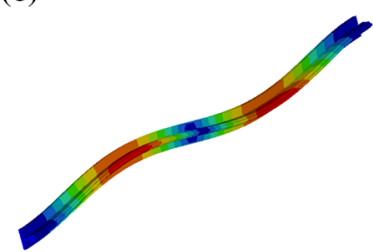

(e)

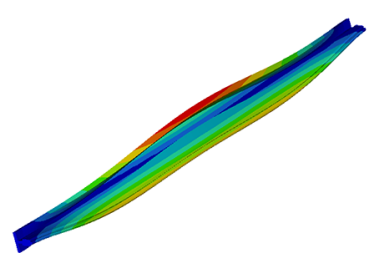

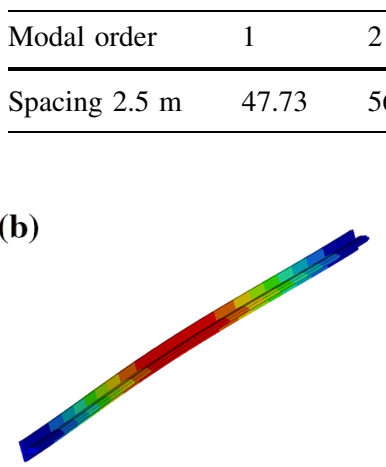

(d)

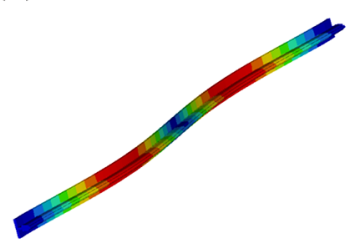

(f)

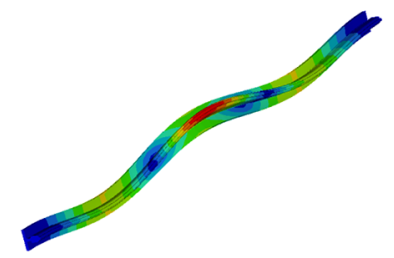

Fig. 3 The first six order vibration modes of the catenary. a Firstorder modal shapes of catenary. b Second-order modal shapes of catenary. c Third-order modal shapes of catenary. d Forth-order modal shapes of catenary. e Fifth-order modal shapes of catenary. f Sixth-order modal shapes of catenary

Table 2 The modal characteristics of the pantograph rigid body model

\begin{tabular}{lll}
\hline Modal & Vibration type & Frequency $(\mathrm{Hz})$ \\
\hline 1 & Transverse movement of pantograph head & 1.51 \\
2 & Raise and fall pantograph & 8.77 \\
\hline
\end{tabular}

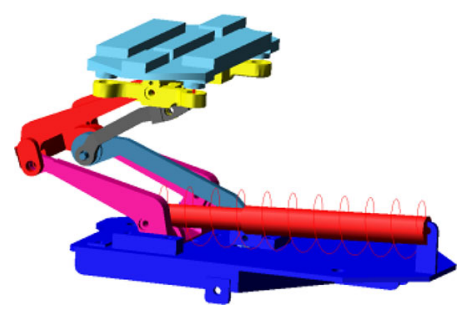

Fig. 4 Dynamic characteristics analysis of pantograph a pantograph. The modal characteristics of the pantograph rigid body model are shown in Table 2 .

\subsection{Dynamic Simulation Model of "Vehicle-Track Beam-Pantograph"}

The bogie model equipped with a pantograph system is shown in Fig. 5; each bogie is fitted with two pantograph models at the pantograph mounting support [5, 6].

After each subsystem model is assembled together, the dynamic simulation model of single vehicle is then completed [7]. The dynamic simulation model of single vehicle is shown in Fig. 6.

\section{Frequency Spectrum Analysis of Contact Force Response of Pantograph-Catenary}

The road stochastic excitation is the input of pantographcatenary coupling dynamics simulation in this paper, so the excitation of the pavement has an important influence on the response of the coupled system. In order to find the frequency range and dominant frequency of contact force vibration, this paper analyzed the frequency spectrum of contact forces under the condition of motion in curved track and straight track at different speeds [8-10].

Figure 7 shows the characteristics of the contact forces in response to the pantograph-catenary system's frequency when the vehicle passes through a straight track. The speeds of the vehicle are 20,40, 60 and $80 \mathrm{~km} / \mathrm{h}$.

As shown in Fig. 7, when the vehicle runs at different speeds, the vibration of the contact force of pantographcatenary subsystem mainly comes from the low-frequency contribution, and there is no high-frequency contribution. The dominant frequency of contact force is about $4.3 \mathrm{~Hz}$.

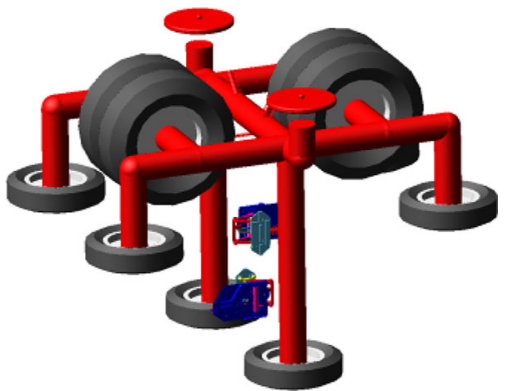

Fig. 5 The bogie model equipped with pantograph system 


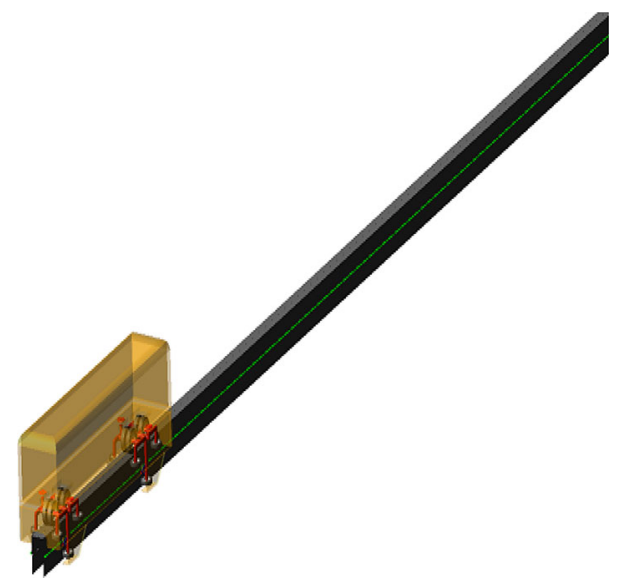

Fig. 6 Dynamic simulation model of single vehicle

Figure 8 shows the characteristics of contact forces in response to pantograph-catenary system's frequency when the vehicle passes through the curved track of R100. The speeds of the vehicle are 20,30 and $40 \mathrm{~km} / \mathrm{h}$.

As it can be seen from Fig. 8, when the vehicle passes through the curved track of R100, with the increase in the running speed of a vehicle, the range of vibration frequency of the contact force between the pantograph and catenary is gradually enlarged.

As it can be seen from Figs. 7 and 8, when the vehicle is passing through the curved track, the vibration frequency of the contact force is larger than that which is passing through the straight track at the same speed.

\section{The Influence of Pantograph Head Parameter on Power Collection Quality}

This paper researched on the influence of pantograph head parameters on the power collection quality under the condition of motion in a curved track with a radius of $100 \mathrm{~m}$. The pantograph head parameters are the weight of pantograph head parts, the stiffness of pantograph head elastic element and the damping of pantograph head elastic element.

\subsection{The Influence of Weight of Pantograph Head Parts on Power Collection Quality}

The contact force between the pantograph head and catenary is provided by the pantograph head spring system, so the weight of pantograph head will affect the following pantograph head.

In the actual operation of straddle-type monorail, the weight of the pantograph head is set to $1,3,5$ and $7 \mathrm{~kg}$, and then, the influence of the weight of the pantograph head on the power collection quality is analyzed.

As it can be seen from Figs. 9 and 10, with the increase in the weight of a pantograph head, the pantograph's standard deviation of contact force and the fluctuation of contact force become larger which occurs on the left and right of the bogie. Therefore, reducing the weight of pantograph head can improve the power collection quality.
Fig. 7 Frequency spectrum of contact force in straight track. a Speed $20 \mathrm{~km} / \mathrm{h}$ right pantograph. b Speed $40 \mathrm{~km} / \mathrm{h}$ right pantograph. c Speed $60 \mathrm{~km} / \mathrm{h}$ right pantograph. d Speed $80 \mathrm{~km} / \mathrm{h}$ right pantograph
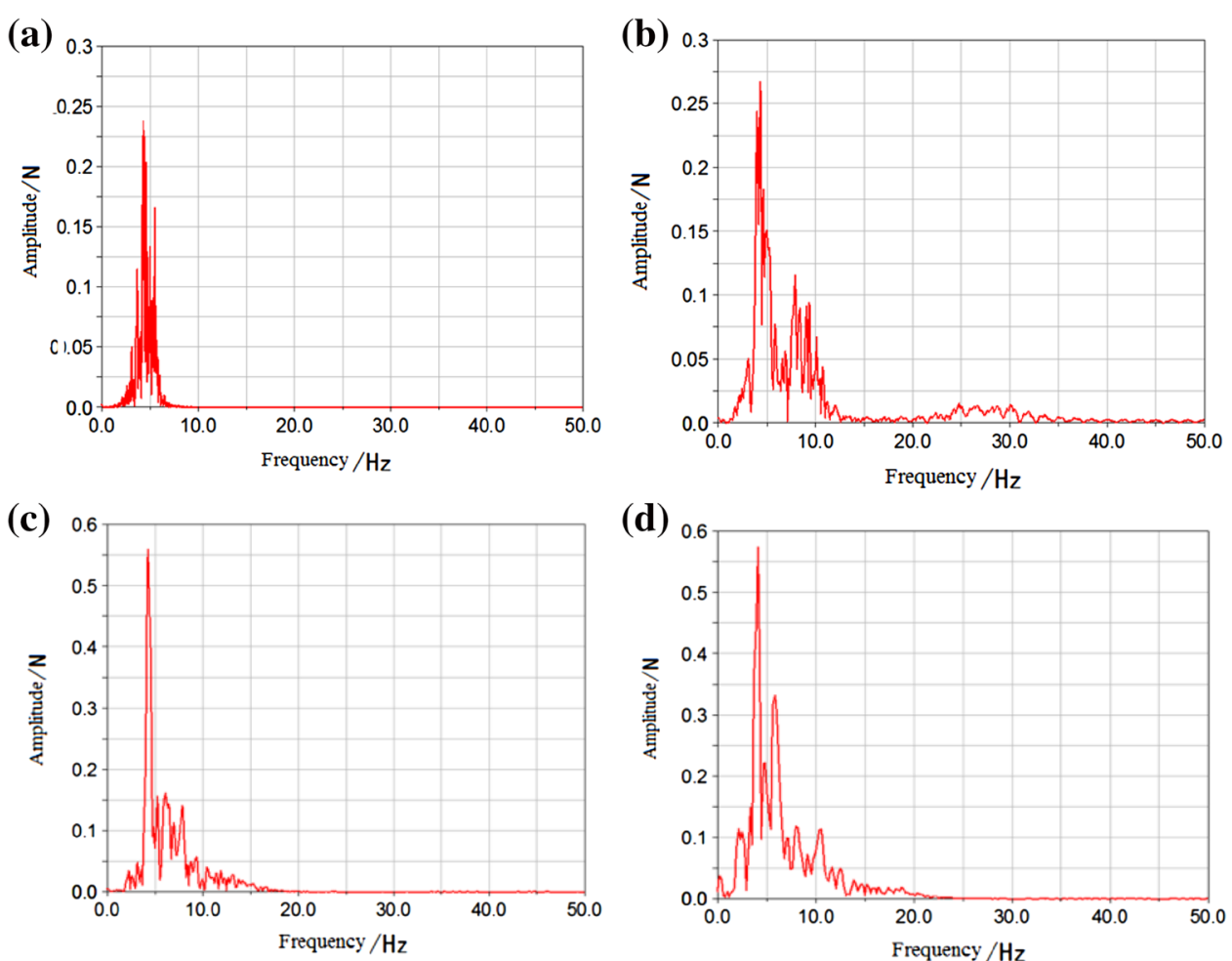
Fig. 8 Frequency spectrum of the contact force in curved track. a Speed $20 \mathrm{~km} / \mathrm{h}$ left pantograph. b Speed $20 \mathrm{~km} / \mathrm{h}$ right pantograph. c Speed $30 \mathrm{~km} / \mathrm{h}$ left pantograph. d Speed $30 \mathrm{~km} / \mathrm{h}$ right pantograph. e Speed $40 \mathrm{~km} / \mathrm{h}$ left pantograph. f Speed $40 \mathrm{~km} /$ $\mathrm{h}$ right pantograph
Fig. 9 The influence of the weight of left pantograph head parts on power collection quality in curve track (a)

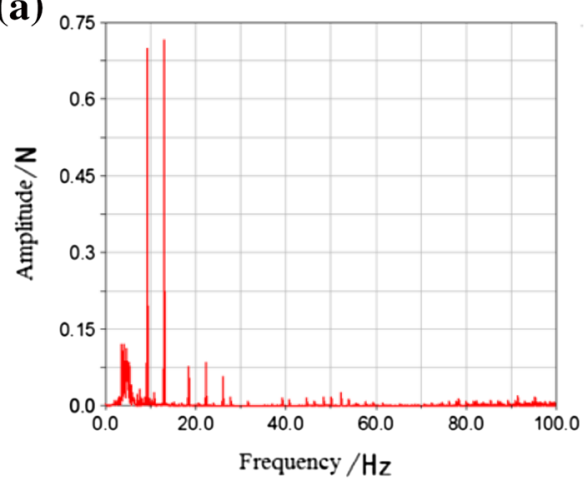

(c)

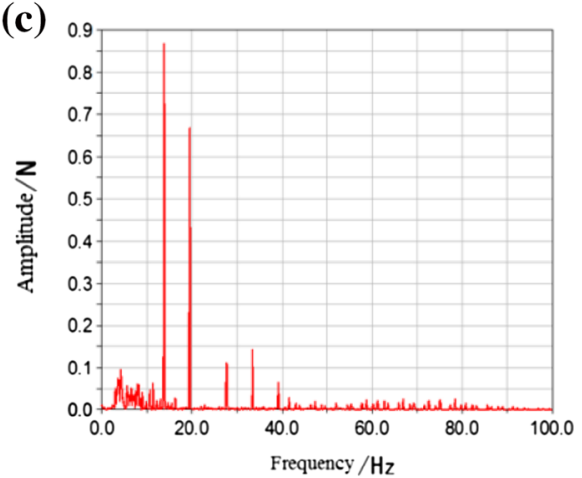

(e)
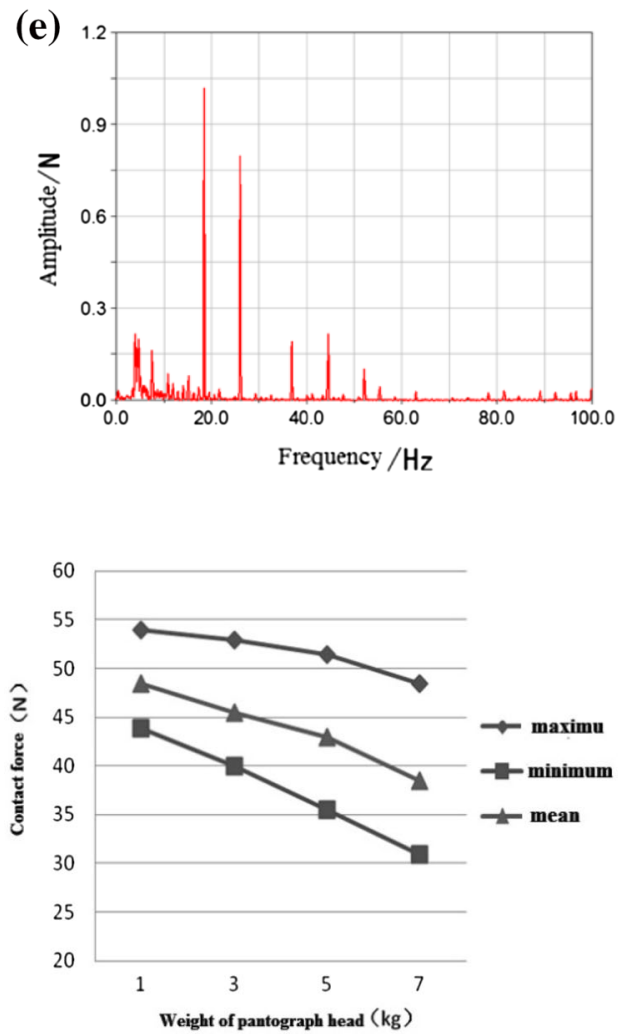

(b)

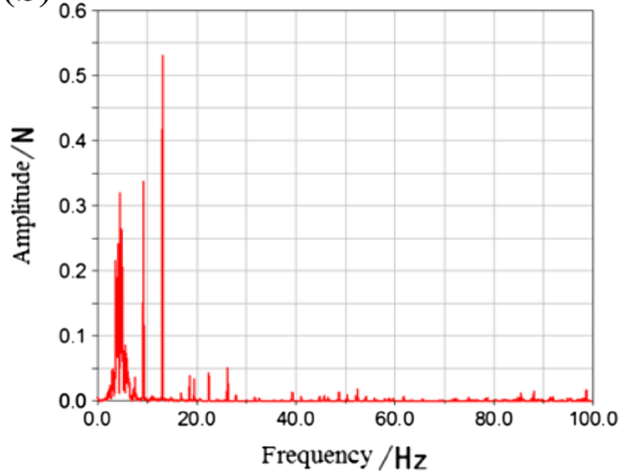

(d)

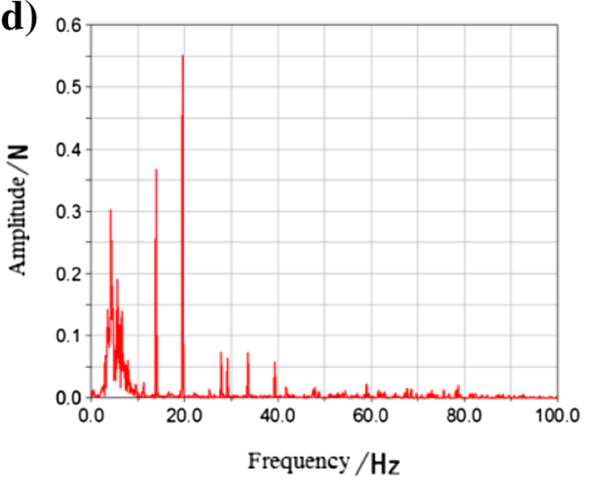

(f)
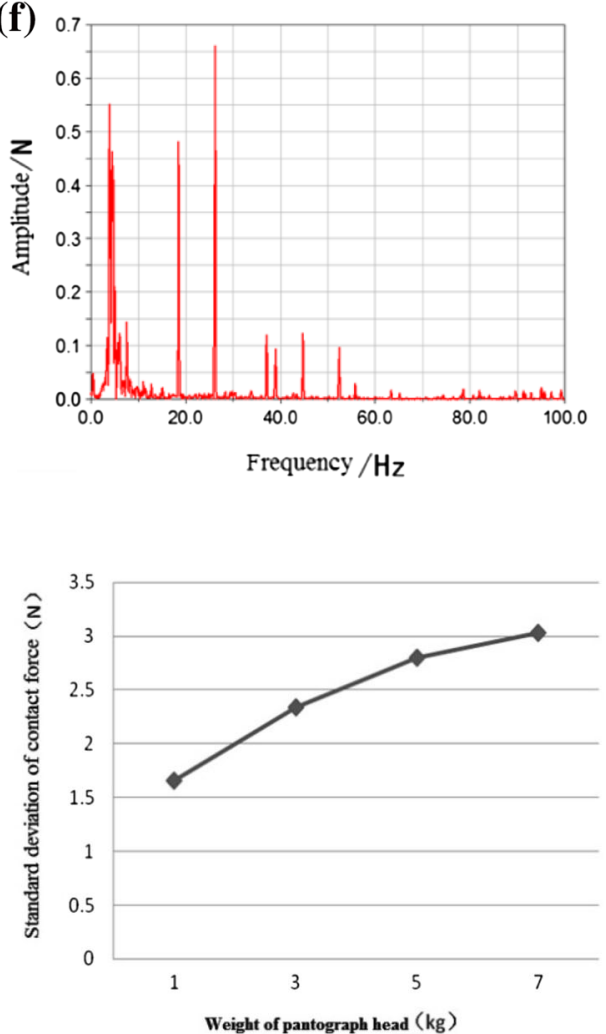
Fig. 10 The influence of weight of right pantograph head parts on power collection quality in curved track

Fig. 11 The influence of stiffness of left pantograph head elastic element on power collection quality in curved track

Fig. 12 The influence of stiffness of right pantograph head elastic element on power collection quality in curved track
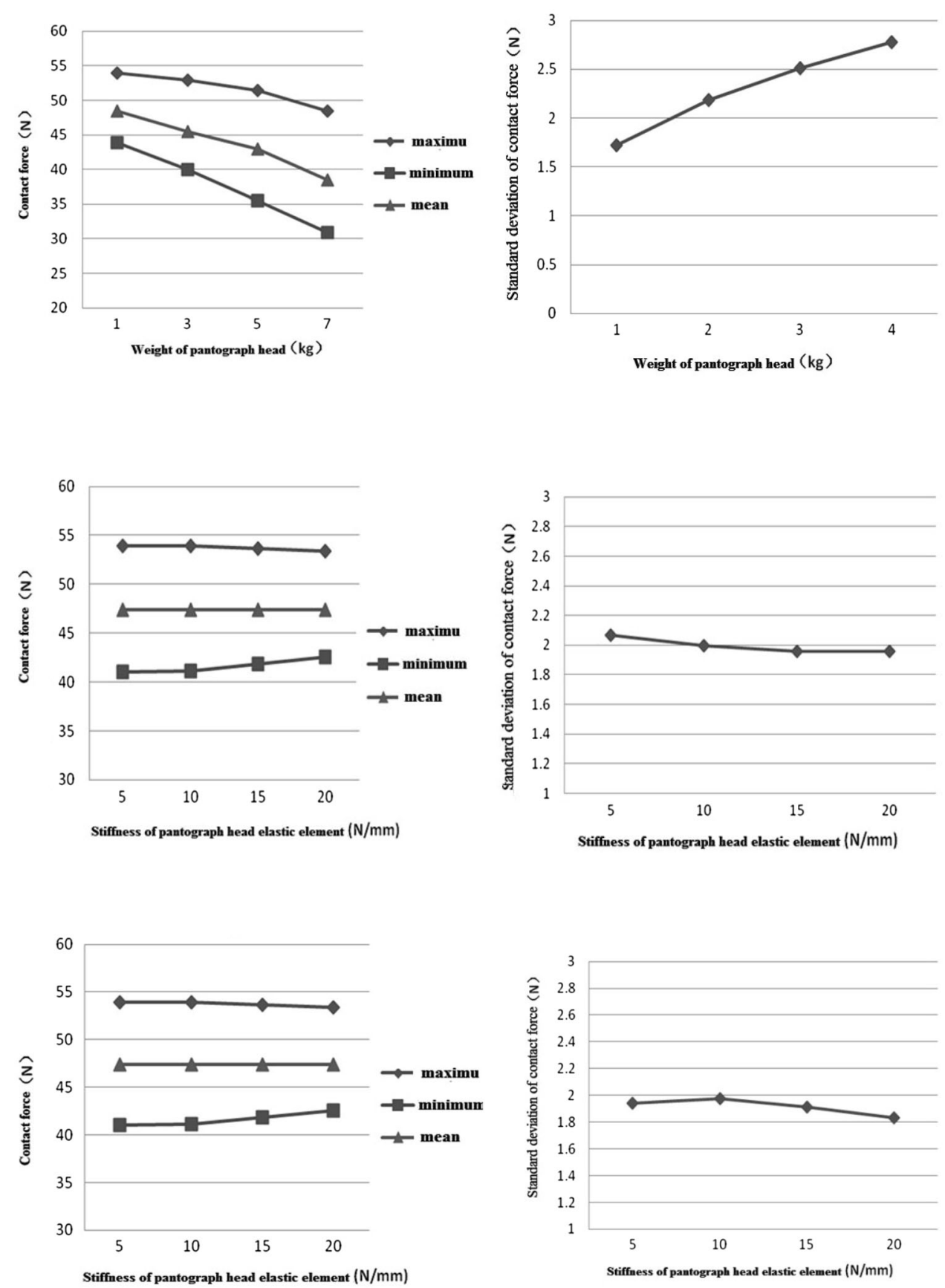

\subsection{The Influence of Stiffness of Pantograph Head Elastic Element on Power Collection Quality}

The stiffness of the pantograph head elastic element is set to $5,10,15$ and $20 \mathrm{~N} / \mathrm{mm}$, and the influence of stiffness of pantograph head elastic element on power collection quality is then analyzed.

As it can be seen from Figs. 11 and 12, with the increase in stiffness of pantograph head elastic element, the pantograph's standard deviation of contact force decreases and the fluctuation of contact force becomes smaller which occurs on the left and right of the bogie. Therefore, increasing the stiffness of the pantograph head elastic element can improve the power collection quality.

\subsection{The Influence of Damping of Pantograph Head Elastic Element on Power Collection Quality}

The damping of the pantograph head elastic element is set to $0,50,100,150$ and $200 \mathrm{Ns} / \mathrm{m}$, and the influence of damping of pantograph head elastic element on power collection quality is then analyzed. 
Fig. 13 The influence of damping of left pantograph head elastic element on power collection quality in curved track

Fig. 14 The influence of damping of right pantograph head elastic element on power collection quality in curved track
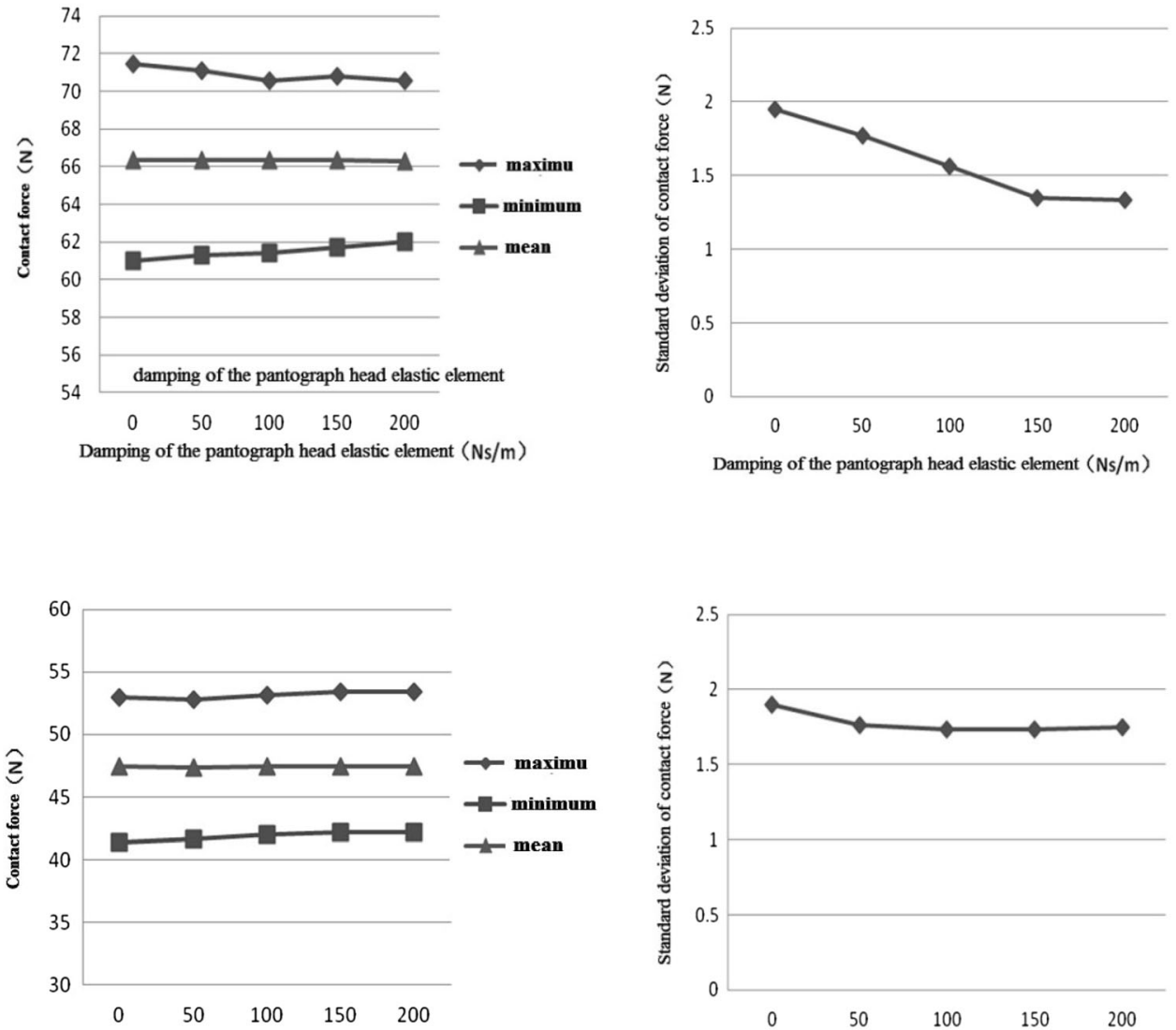

Damping of the pantograph head elastic element $(\mathrm{Ns} / \mathrm{m})$

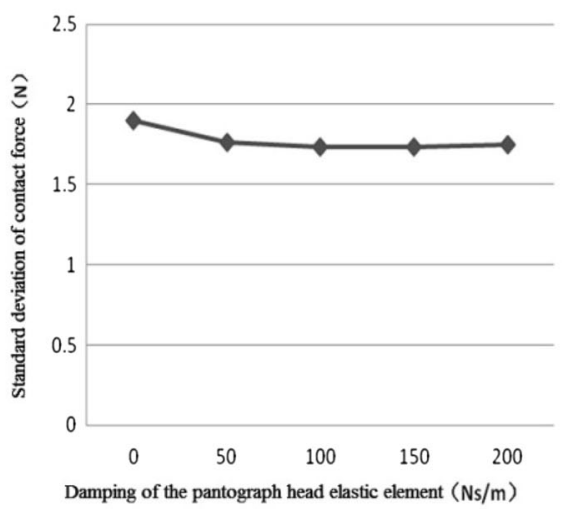

As it can be seen from Figs. 13 and 14: with the increase in damping of pantograph head elastic element, the pantograph's standard deviation of contact force decreases and the fluctuation of contact force becomes smaller which occurs on the left and right of the bogie. Therefore, increasing the damping of pantograph head elastic element can improve the power collection quality.

\section{Conclusion}

This paper established a dynamic computational model of pantograph and a rigid-flexible coupling dynamic model of pantograph-catenary system. Through an analysis of the computer simulation, when the vehicle runs at different speeds, the dominant frequency of the contact force of pantograph-catenary subsystem is about $4.3 \mathrm{~Hz}$.

This paper researched on the influence of pantograph head parameters on the power collection quality. Reducing the weight of the pantograph head, increasing the stiffness of pantograph head elastic element or increasing the damping of pantograph head elastic element can improve the power collection quality to a certain extent.

But there are still some shortcomings:
Due to the limited conditions, when the rigid-flexible coupling dynamic model of pantograph-catenary system is being established, the stochastic excitation of the contact wire surface is not taken into account. Therefore, there is a certain deviation between the simulation results and the actual situation.

Acknowledgements The project titled Research on the Mechanism and Control Method of Monorail Trains Running Tires' Shoulder Wear, Project Number: 51475062 was funded by National Natural Science Foundation of China.

Open Access This article is distributed under the terms of the Creative Commons Attribution 4.0 International License (http://crea tivecommons.org/licenses/by/4.0/), which permits unrestricted use, distribution, and reproduction in any medium, provided you give appropriate credit to the original author(s) and the source, provide a link to the Creative Commons license, and indicate if changes were made.

\section{References}

1. Zhong J, Du Z, He X (2013) Turnout structure and analysis of monorail vehicle. People Communications Press, Beijing

2. Duan Y (2009) Failure analysis of Chong Qing straddle type monorail vehicle's Pantograph. Chongqing University, Chongqing 
3. Poetsch G, Evans J, Meisinger R et al (2007) Pantograph/catenary dynamics and control. Veh Syst Dyn 28(2):159-195

4. Rauter FG, Pombo J, Ambrósio J et al (2007) Multibody modeling of pantographs for pantograph-catenary interaction. IUTAM Bookseries 1:205-226

5. Zixue D, Li Y, Liang Z, Wen X (2016) Research on curve through safety of straddle-type monorail vehicle. Electric Drive Locomot 1:79-83

6. Zixue D, Chen C, Shen Z, Liu Y, Gao L, Zhong Y, Zhang Y (2015) Study of the negotiation stability for straddle-type monorail train under cross-wind condition. Electric Drive Locomot 5:60-64
7. Du Z, Cao D (2016) Influence of air spring failure on operation safety for straddle-type monorail vehicle. Electric Drive Locomot 5:76-80

8. Link DIM, von Berechnung Z (1980) Fahrleitungsschwingungen mit Hilfe frequenzabhängiger finiter Elemente. Arch Appl Mech 51(1):45-60

9. Brodkorb A, Semrau M (1993) Simulationsmodell des systems oberleitungskettenwerk und stormabnehmer. Elektrische Bahnen. 91(4):105-113

10. Reichmann T (2005) Simulation des systems oberleitungs-kettenwerk und stromabnehmer mit der Finite-Elemente-Methode. Elektrische Bahnen 103(1):69-75 